\title{
DIVERSION OF THE MELANIN SYNTHETIC PATHWAY BY DOPAMINE PRODUCT SCAVENGERS: A QUANTUM CHEMICAL MODELING OF THE REACTION MECHANISMS
}

\author{
Taye B. Demissie ${ }^{1 *}$ and Getinet Y. Ashebir ${ }^{2}$ \\ ${ }^{1}$ Centre for Theoretical and Computational Chemistry, Department of Chemistry, UiT The \\ Arctic University of Norway, 9037 Tromsø, Norway \\ ${ }^{2}$ NanoSciences Innovation Centre, Department of Physics, University of Cape Town, \\ Rondebosch 7701, South Africa
}

(Received April 7, 2014; revised August 2, 2016)

\begin{abstract}
We report the stability and reactivity of the oxidation products as well as L-cysteine and Nacetylcysteine adducts of dopamine studied using quantum chemical calculations. The overall reactions studied were subdivided into four reaction channels. The first reaction channel is the oxidation of dopamine to form dopaminoquinone. The second reaction channel leads to melanin formation through subsequent reactions. The third and fourth reaction channels are reactions leading to the formation of dopaminoquinone adducts which are aimed to divert the synthesis of melanin. The results indicate that L-cysteine and N-acetylcysteine undergo chemical reactions mainly at C5 position of dopaminoquinone. The analyses of the thermodynamic energies indicate that L-cysteine and $\mathrm{N}$-acetylcysteine covalently bind to dopaminoquinone by competing with the internal cyclization reaction of dopaminoquinone which leads to the synthesis of melanin. The analysis of the results, based on the reaction free energies, is also supported by the investigation of the natural bond orbitals of the reactants and products.
\end{abstract}

KEY WORDS: Dopamine, Melanin, L-Cysteine, N-Acetylcysteine, DFT calculations

\section{INTRODUCTION}

Melanin is the pigment that determines the color of the skin. It is synthesized by the melanocytes in the basal layer of the epidermis [1]. The pigments of melanin are of two types, eumelanin and pheomelanin. Eumelanin is black or brown and pheomelanin is red or yellow [2, 3]. The amino acid tyrosine and the enzyme tyrosinase play the main role for the synthesis of eumelanin and pheomelanin [4]. Tyrosinase catalyzes the conversion of tyrosine into biochemical intermediates dopa and dopaminoquinone. The latter is the precursor of both eumelanin and pheomelanin in the process of melanogenesis that synthesizes the melanin pigment [2, 4]. Dopamine oxidation and melanin formation might also be associated with Parkinson's disease, where dopamine-containing cells in the nervous system are susceptible to degeneration $[5,6]$. The ratio of these two pigments in the skin determines how dark or light the skin color will be [7, 8]. Differences in the ratio of melanin pigments create wide variations in human skin color, ranging from light to dark skin color. Thus, when the eumelanin to pheomelanin ratio is higher the skin of an individual becomes darker. To lighten skin, dopaminoquinone has to be diverted towards the production of pheomelanin by increasing the amount of sulfur inside the cells [2, 3, 7]. Melanogenesis automatically leads to an increased synthesis of sulfhydryl-dopa conjugates. This causes the synthesis of the lighter colored pheomelanin instead of the darker colored eumelanin by preventing the overproduction of melanin in the presence of a high intracellular sulfur concentration $[9,10]$.

Studies have been reported about the physiological regulation of the depigmentation of human melanoma cells and melanocytes using cystamine [3]. The inhibition of the synthesis of melanin using Lespedeza cyrtobotrya [11], Lespedeza floribunda and Balanophora fungosa [12]

*Corresponding author. E-mail: sene3095@gmail.com 
is also reported. A study about the promotion of respiration-dependent $\mathrm{H}_{2} \mathrm{O}_{2}$ production in mitochondria by dopamine oxidation products has also been reported [13]. The use of cystamine in melanin regulation is found to be nontoxic [3]. Accordingly, thiols are good compounds to divert melanin synthesis. They react with the quinone intermediates so that the pigment synthesis from eumelanin (black) to pheomelanin (red or yellow) take place [3]. An elevated level of thiols, including glutathione derivatives, have been linked to pheomelanin formation or lack of pigment in humans $[14,15]$ and in mice [16]. Cystamine has also been used to relieve cysteine accumulation in cystic fibrosis patients [17]. In cultured cells, cystamine promotes the uptake of cysteine via a glutamate-sensitive transporter with consequent increased synthesis of glutathione [18]. Other study showed that cystamine can also inhibit human immunodeficiency virus replication [19].

The physiological relevance of gluthathionyl and its derivatives (like 5-S-glutathionyldopamine) is also related to neuroprotective reactions. These reactions, for instance, are supported by the formation of 5-S-glutathionyl- and 5-S-cysteinyl-dopamine which prevent dopamine-mediated DNA damage [20, 21]. 5-S-cysteinyldopamine occurs in dopaminergic brain regions and dopamine undergoes autoxidation which can lead to the formation of highly reactive quinones like dopaminoquinone. This may result in cytotoxicity, leading to aging and brain disorders $[22,23]$. On the other hand, gluthathione and related species are capable of stimulating collagen synthesis, a property which is responsible for the suitability of these substances for the regulation of melanin synthesis. And also, by increasing the collagen production it has been made possible to control and remove wrinkles on human body [24, 25]. However, the understanding of how melanin synthesis is regulated in the human body still needs more study even though a number of studies have been reported.

Nishihira et al. [26] reported a theoretical study on the protonation-deprotonation mechanism of the hydroxyl groups of dopamine. Aliste [27] also reported the theoretical study of the drug-receptor interaction of dopamine. Mohammad-Shiri et al. reported theoretical study of the transformation of dopaminoquinone to dopamine [28]. However, to the best of our knowledge, there are no computational studies about diversion of the melanin synthetic pathways. Hence, the main objective of this study was to analyze whether the dopamine oxidation products and derivatives are thermodynamically stable, and moreover to assess the efficiency of L-cysteine (cyst) and $\mathrm{N}$-acetylcysteine (ncyst) in diverting the synthesis of melanin using quantum chemical calculations. Emphasis was also given to the identification of the synthetic pathways of melanin and diversion of its reaction pathway based on the change in energies of the reactants and products. We note that very accurate predictions can be made using multiconfigurational approaches than the most commonly used density functional theory (DFT) approaches [29-32], even though DFT also provides qualitatively correct results. Therefore, believing that this work should be helpful for the understanding of the melanin synthetic pathway as well as its inhibition at the molecular level, we present the comparisons and analyses of the reaction mechanisms using standard density functional theory calculations.

\section{COMPUTATIONAL DETAILS}

All the geometries of the molecules studied were optimized employing the B3LYP [33-36] functional. The 6-311++G(2df,2p) [37] basis set was used for the optimizations and frequency calculations. Second order Møller-Plesset (MP2) [38, 39] frequency and single point calculations on the B3LYP optimized geometries were also performed using the same basis set for further confirmation of the results. All the calculations were performed by imposing standard conditions for temperature $(298.15 \mathrm{~K})$ and pressure $(1.00 \mathrm{~atm})$ using Gaussian 09 program package [40]. Solvent effects were corrected by using the polarizable continuum model (PCM) in its integral equation formalism (IEF) [41] and water as a solvent to mimic the biological processes. Natural bond orbital (NBO) analysis $[42,43]$ was used to explore the charges on the 
atoms before and after the formation of new bonds during the chemical reactions. The reactants as well as products have been assessed based on the potential energy surfaces (PES) and the geometry corresponding to the global minimum of the PES was considered for further calculations for each molecule. As there are many possible low energy conformations for some of the molecules, additional conformational analyses by reorienting the side attachments in different orientations were also done to identify the most stable conformers. The geometries obtained from these conformational analyses were used for further refined geometry optimizations and frequency calculations. The optimized structures of all reactants and products were confirmed by frequency calculations to be real minima without any imaginary vibrational frequency. For the transition state structures, the geometries were optimized using the same level of calculations and frequency calculations were also performed to confirm the presence of one and only one imaginary vibrational frequency. The stabilization energy gained by donation from the donor NBO to the acceptor NBO $(E(2))$ is estimated based on the second order perturbation theory analysis of the Fock Matrix in NBO basis [44, 45]. The changes in the thermodynamic properties were computed by subtracting the sum of the thermodynamic property of the reactants from the sum of the thermodynamic property of the products, as we did in our previous study [46], i.e.

$$
\Delta G=\sum G_{\text {products }}-\sum G_{\text {reactants }} \text { and } \Delta E=\sum E_{\text {products }}-\sum E_{\text {reactants }} .
$$

The atom numbering followed throughout the paper is given in Figure 1 together with the structures of the molecules considered, namely L-cysteine (cyst), N-acetylcysteine (ncyst), dopamine (DA), dopaminoquinone (DAQ), aminochrome (AC), leukoaminochrome (LAC), 5,6-dihydroxyindole (DHI), 5-cysteinyldopamine (5-CDA), 6-cysteinyldopamine (6-CDA), 5(N-acetylcysteinyl)dopamine (5-NCDA) and 6-(N-acetylcysteinyl)dopamine (6-NCDA).<smiles>NC(CS)C(=O)O</smiles>

cyst<smiles>CC(=O)NC(C[Hg])C(=O)O</smiles><smiles>Oc1cc2cc[nH]c2cc1[Hg]</smiles>
5,6-DHI<smiles>NCCc1ccc(O)c(O)c1</smiles>

DA<smiles>NCCC1=CC(=O)C(=O)C=C1</smiles><smiles>O=C1C=C2CCNC2=CC1=O</smiles><smiles>[R]c1c(CCN)cc(O)c(O)c1[R]</smiles>

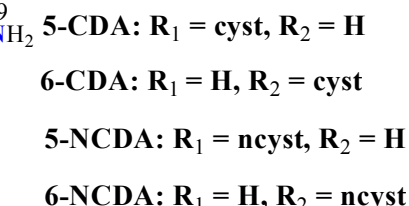<smiles>Oc1cc2c(cc1O)NCC2</smiles>

LAC

Figure 1. Structures of the molecules with atom numbering.

The reaction channels 1 and 2 , leading to the formation of melanin, are summarized in Scheme 1, with the details of channel 2 in Scheme 2. The highlight for the possible reactions leading to the diversion of melanin synthesis (reaction channel 3) is also shown in Scheme 1, 
with the details presented in Scheme 3. The first reaction considered, reaction channel 1, is the oxidation of DA to form DAQ (see Scheme 1). Channel 2 is the internal cyclization of DAQ to form a five-member ring leading to $\mathrm{DHI}$ and by consequent polymerization reactions to the synthesis of melanin. Channel 3 is a reaction mechanism aimed to divert the melanin synthesis by forming 5-CDA and 6-CDA (vide infra). The analyses of the reaction mechanisms are presented in three sections, first in the Reaction channels 1 and 2 section, second The Scavengers and the last is the Reaction channels 3 and 4. Since the B3LYP and MP2 results show the same trends (vide infra), mainly the results obtained from the B3LYP calculations are cited in the discussion.

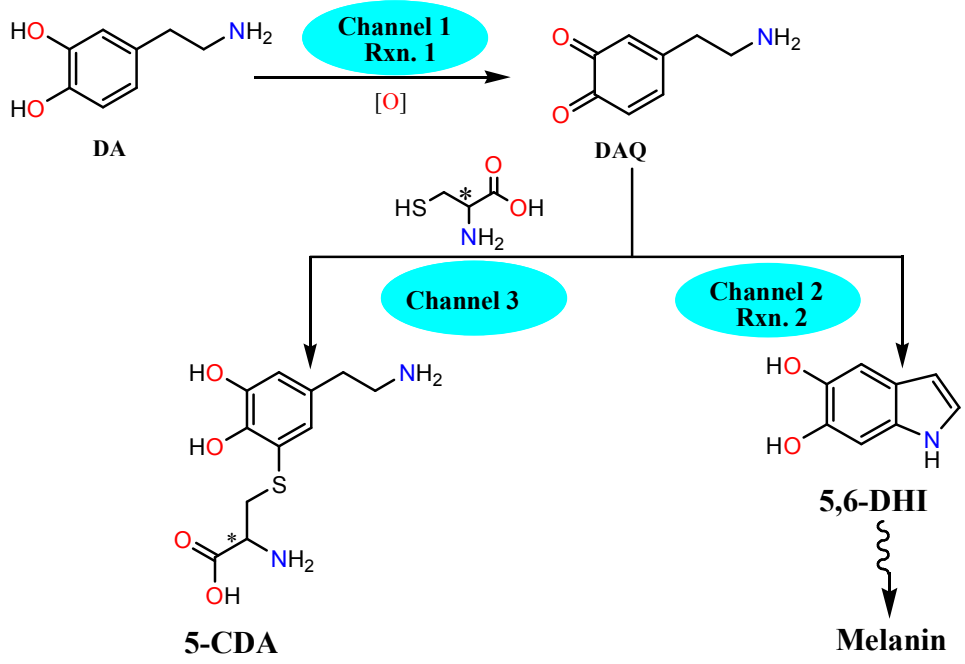

Scheme 1. The two possible reaction pathways of dopaminoquinone in the absence of the scavengers (channel 2) and presence of the scavengers (channel 3). Refer to Table 3 for the reaction numbers.

Reaction channels 1 and 2

In this section of the paper, we present the intermediate and final products from the internal cyclization reaction of DAQ in an attempt to identify the convenient steps to divert the synthesis of melanin. The reaction channels 1 and 2 studied in this section of the paper are shown in Scheme 1, whereas the natural charges from the NBO analysis and the Mulliken charges are listed in Table 1. Selected structural parameters are presented in Table 2. The change in Gibbs free energy and total electronic energies for the reactions are listed in Tables 3. As shown in Scheme 1, after oxidation of DA to DAQ, the DAQ confronts two possible reactions pathways. The first is undergoing cyclization reaction to form $\mathrm{AC}$ [47] followed by subsequent polymerization steps to form neuromelanin. The second is to undergo covalent conjugation of DAQ with sulfhydryl compounds, like L-cysteine (cyst), N-acetylcysteine (ncyst) and glutathione, which lead to the diversion of the melanin synthetic reaction pathway [48].

The NBO and Mulliken charge analysis of DAQ shows that the nitrogen atom of the amine group of DAQ is negatively charged. Hence, in the absence of reductants (for instance sulfhydryl compounds), the ethylamine side chain of DAQ itself acts as an internal nucleophile and attacks C6 of DAQ. The immediate product formed in this process is leukoaminochrome (LAC) which leads to the formation of DHI (see Scheme 2). The bond stabilization energy from second order perturbation theory analysis of the Fock matrix in NBO for the newly formed C-N 
bond of DHI during the cyclization reaction is $25.8 \mathrm{~kJ} / \mathrm{mol}$. DHI is therefore the most stable product in reaction channel 2 and an intermediate in melanin synthesis (see Scheme 2).

Table 1. Selected natural atomic charges from NBO calculations (without parentheses) and Mulliken charges (in parentheses) of the major molecules in the reaction channels, all calculated using B3LYP/6-311++G(2df,2p).

\begin{tabular}{|c|c|c|c|c|c|c|c|c|c|c|}
\hline Compound & $\mathrm{C} 2$ & C5 & C6 & $\mathrm{C} 2^{\prime}$ & $\mathrm{N}^{\prime}$ & $\mathrm{H}\left(\mathrm{N} 5^{\prime}\right)$ & $\mathrm{S} 1^{\prime}$ & $\mathrm{H}(\mathrm{SH})$ & $\mathrm{O}^{\prime}$ & $\mathrm{H}\left(\mathrm{O} 6^{\prime} \mathrm{H}\right)$ \\
\hline Cyst & - & - & - & $\begin{array}{c}-0.501 \\
(-0.425)\end{array}$ & $\begin{array}{c}-0.871 \\
(-0.321) \\
\end{array}$ & $\begin{array}{c}+0.398 \\
(+0.227)\end{array}$ & $\begin{array}{c}-0.051 \\
(-0.576) \\
\end{array}$ & \begin{tabular}{|c|}
+0.122 \\
$(+0.196)$
\end{tabular} & $\begin{array}{c}-0.703 \\
(-0.422) \\
\end{array}$ & $\begin{array}{c}+0.480 \\
(+0.345) \\
\end{array}$ \\
\hline Ncyst & - & - & - & $\begin{array}{c}-0.510 \\
(-0.039)\end{array}$ & $\begin{array}{c}-0.625 \\
(-0.016) \\
\end{array}$ & $\begin{array}{c}+0.396 \\
(+0.291) \\
\end{array}$ & $\begin{array}{c}-0.014 \\
(-0.269) \\
\end{array}$ & $\begin{array}{c}+0.107 \\
(+0.180) \\
\end{array}$ & $\begin{array}{c}-0.703 \\
(-0.319) \\
\end{array}$ & $\begin{array}{c}+0.504 \\
(+0.326) \\
\end{array}$ \\
\hline DA & $\begin{array}{c}-0.238 \\
(-0.361) \\
\end{array}$ & $\begin{array}{c}-0.212 \\
(+0.115) \\
\end{array}$ & $\begin{array}{c}-0.258 \\
(-0.764) \\
\end{array}$ & - & - & - & - & - & - & - \\
\hline DAQ & $\begin{array}{c}-0.262 \\
(-0.481)\end{array}$ & $\begin{array}{l}(-0.015) \\
(+0.077)\end{array}$ & $\begin{array}{c}-0.242 \\
(-0.640)\end{array}$ & - & $\begin{array}{c}-0.850 \\
(-0.385)\end{array}$ & $\begin{array}{c}+0.360 \\
(+0.187)\end{array}$ & - & - & - & - \\
\hline DHI & $\begin{array}{c}-0.253 \\
(-0.743) \\
\end{array}$ & $\begin{array}{c}-0.274 \\
(-0.610) \\
\end{array}$ & $\begin{array}{c}-0.155 \\
(-0.102) \\
\end{array}$ & - & - & - & - & - & - & - \\
\hline $\mathrm{AC}$ & $\begin{array}{c}-0.245 \\
(-0.805) \\
\end{array}$ & $\begin{array}{c}-0.378 \\
(-0.766) \\
\end{array}$ & $\begin{array}{c}-0.227 \\
(-0.767) \\
\end{array}$ & - & - & - & - & - & - & - \\
\hline 5-CDA & $\begin{array}{c}-0.257 \\
(-0.185)\end{array}$ & $\begin{array}{c}-0.231 \\
(+1.429)\end{array}$ & $\begin{array}{c}-0.194 \\
(-1.034) \\
\end{array}$ & $\begin{array}{c}-0.499 \\
(-0.020)\end{array}$ & $\begin{array}{c}-0.890 \\
(-0.246)\end{array}$ & $\begin{array}{c}+0.371 \\
(+0.223)\end{array}$ & $\begin{array}{c}+0.238 \\
(-0.675)\end{array}$ & - & $\begin{array}{c}-0.697 \\
(-0.271)\end{array}$ & $\begin{array}{c}+0.504 \\
(+0.297)\end{array}$ \\
\hline 5-NCDA & $\begin{array}{c}-0.352 \\
(-0.504) \\
\end{array}$ & $\begin{array}{c}-0.244 \\
(+1.913) \\
\end{array}$ & $\begin{array}{c}-0.211 \\
(-0.938) \\
\end{array}$ & $\begin{array}{c}-0.492 \\
(+0.184) \\
\end{array}$ & $\begin{array}{c}-0.644 \\
(+0.108) \\
\end{array}$ & $\begin{array}{c}+0.412 \\
(+0.266) \\
\end{array}$ & $\begin{array}{c}+0.223 \\
(-0.849) \\
\end{array}$ & - & $\begin{array}{c}-0.677 \\
(-0.228) \\
\end{array}$ & $\begin{array}{c}+0.492 \\
(+0.324) \\
\end{array}$ \\
\hline 6-CDA & $\begin{array}{c}-0.256 \\
(-0.102) \\
\end{array}$ & $\begin{array}{c}-0.221 \\
(-0.116) \\
\end{array}$ & $\begin{array}{c}-0.208 \\
(+0.839) \\
\end{array}$ & $\begin{array}{c}-0.495 \\
(+0.010) \\
\end{array}$ & $\begin{array}{c}-0.888 \\
(-0.254) \\
\end{array}$ & $\begin{array}{c}+0.381 \\
(+0.222) \\
\end{array}$ & $\begin{array}{c}+0.208 \\
(-0.894) \\
\end{array}$ & - & $\begin{array}{c}-0.696 \\
(-0.235) \\
\end{array}$ & $\begin{array}{c}+0.503 \\
(+0.301) \\
\end{array}$ \\
\hline 6-NCDA & $\begin{array}{c}-0.351 \\
(-0.101)\end{array}$ & $\begin{array}{c}-0.231 \\
(-0.316)\end{array}$ & $\begin{array}{c}-0.215 \\
(+0.818)\end{array}$ & $\begin{array}{c}-0.495 \\
(+0.012)\end{array}$ & $\begin{array}{c}-0.888 \\
(-0.253)\end{array}$ & $\begin{array}{c}+0.381 \\
(+0.223)\end{array}$ & $\begin{array}{c}+0.206 \\
(-0.894)\end{array}$ & - & $\begin{array}{c}-0.676 \\
(-0.224)\end{array}$ & $\begin{array}{c}+0.503 \\
(+0.321)\end{array}$ \\
\hline
\end{tabular}

The change in Gibbs free energies $(\Delta G)$ of the chemical reactions of channel 2 shows that the reaction leading to the formation of $\mathrm{AC}$ is the least stable (compare reactions 2, 5 and 8 in Table 3). This indicates that AC is reactive in channel 2 of Scheme 2. The oxidation reactions in the presence of oxygen are more feasible than the rearrangement reactions due to the susceptibility of the -OH moiety to non-enzymatic oxidation. Especially, the conversion of LAC to $\mathrm{AC}$ is more spontaneous (for instance the B3LYP calculated value of $\Delta G$ is $-268.6 \mathrm{~kJ} / \mathrm{mol}$, see reaction 5 in Table 3) than the conversion of DA to DAQ with a $\Delta G$ value of $-190.3 \mathrm{~kJ} / \mathrm{mol}$ (see reaction 1 in Table 3). This causes high consumption of molecular oxygen during the oxidation process of LAC to AC. This analysis is in agreement with the experimental results for the oxidation of dopamine to aminochrome as a mechanism for the neurodegeneration of dopaminergic systems in Parkinson's disease [47]. We also note that such reactions have been reported for cases characterized by the use of tyrosinase as catalyst [49]. On the other hand, the formation of the intermediate product during the conversion of $\mathrm{AC}$ to $\mathrm{DHI}$ is distinguished by a $\Delta G$ value that is reduced by $-13.0 \mathrm{~kJ} / \mathrm{mol}$ (difference in energy between $\mathrm{AC}$ and IM-AC shown in Scheme 2, the free energy change is also $-16.0 \mathrm{~kJ} / \mathrm{mol}$ ) compared to the conversion of the same intermediate product leading to the formation of DHI. This indicates that excess amount of $\mathrm{AC}$ may stay inside the cell which could result in the conversion of $\mathrm{AC}$ to other reactive species and further leading to hindrance of the synthesis of melanin and neurotoxicity as also indicated in the experimental findings [50-52].

Let us now turn our attention to the kinetic analysis of the internal cyclization reactions of DAQ. The energy profile for the conversion of DAQ to DHI is presented in Figure 2. The first reaction considered is the conversion of DAQ to LAC which involves two transition states. The first transition state $\left(\mathrm{TS}^{2}{ }_{1}\right)$ has a barrier of $37.7 \mathrm{~kJ} / \mathrm{mol}$ relative to the reactants $(21.7 \mathrm{~kJ} / \mathrm{mol}+$ $16.0 \mathrm{~kJ} / \mathrm{mol}$, see Figure 2). $\mathrm{TS}^{2}$ then converts to an intermediate product $\left(\mathrm{IM}^{2}{ }_{1}\right)$ followed by the formation of the second transition state $\left(\mathrm{TS}^{2}{ }_{2}\right)$. $\mathrm{TS}_{2}^{2}$ is favored by $3.2 \mathrm{~kJ} / \mathrm{mol}$ compared to $\mathrm{TS}^{2}{ }_{1}$ 
$(16.0 \mathrm{~kJ} / \mathrm{mol}-12.8 \mathrm{~kJ} / \mathrm{mol})$. Moreover, LAC is stable by $78.7 \mathrm{~kJ} / \mathrm{mol}$ compared to the reactants and by $100.4 \mathrm{~kJ} / \mathrm{mol}$ relative to the intermediate product $(78.7 \mathrm{~kJ} / \mathrm{mol}+21.7 \mathrm{~kJ} / \mathrm{mol}$, see Figure 2 ). This indicates that once DAQ starts the internal cyclization reaction it is less probable to divert it from the synthetic reaction pathway leading to melanin. This is also clearly observed from the NBO and Mulliken charge analyses which both show a negative charge on C5 of both DHI and AC (see Table 1), making it less susceptible to a nucleophilic attack by the scavengers. In other words, nucleophilic attack by the scavengers is impossible once the intermediate products are formed from the internal cyclization reaction. Therefore, the general conclusion from this section of the paper is that the reaction process for the diversion of the melanin synthetic pathway should start before the internal cyclization reaction.

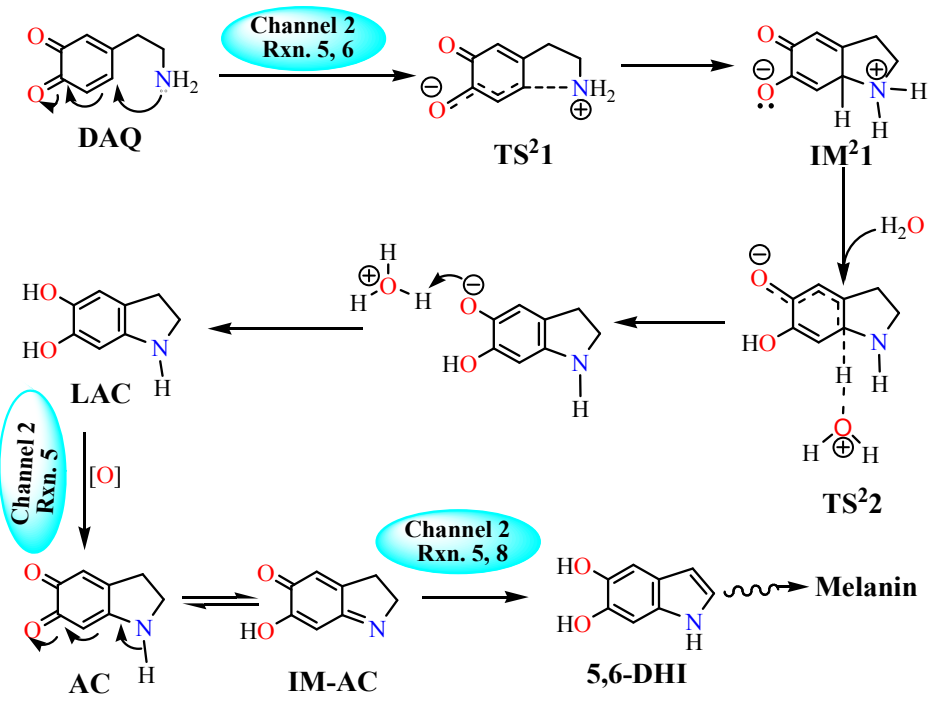

Scheme 2. The reaction mechanism for the synthesis of melanin. For the purpose of clarity some of the steps are omitted. Refer to Table 3 for the reaction numbers.

Table 2. Selected bond lengths $(\AA)$ and angles $\left({ }^{\circ}\right)$ (without parentheses) and bond stabilization energies from second order perturbation theory analysis of the Fock matrix in NBO $(E(2)$ in parentheses, $\mathrm{kJ} / \mathrm{mol})$ of the scavengers and products calculated using B3LYP/6-311++G(2df,2p).

\begin{tabular}{|l|c|c|c|c|c|c|c|c|c|c|}
\hline Compound & C1-C6 & C4-C5 & C5-C6 & C5-S & C6-S & C2'-S & C1C6C5 & C4C5C6 & C5SC2' & C6SC2' \\
\hline DAQ & 1.465 & 1.459 & 1.349 & - & - & - & 123.2 & 119.9 & - & - \\
& $(26.2)$ & $(79.5)$ & $(48.8)$ & - & - & - & - & - & - & - \\
\hline Cyst & - & - & - & - & - & 1.821 & - & - & - & - \\
& - & - & - & - & - & $(11.7)$ & - & - & - & - \\
\hline Ncyst & - & - & - & - & - & 1.828 & - & - & - & - \\
& - & - & - & - & - & $(11.5)$ & - & - & - & - \\
\hline 5-CDA & 1.391 & 1.395 & 1.399 & 1.782 & - & 1.782 & 121.7 & 119.4 & 101.7 & - \\
& $(253.3)$ & $(123.0)$ & $(42.5)$ & $(19.2)$ & - & $(16.5)$ & - & - & - & - \\
\hline 5-NCDA & 1.391 & 1.395 & 1.398 & 1.786 & - & 1.786 & 121.6 & 119.4 & 104.5 & - \\
& $(223.1)$ & $(118.0)$ & $(42.0)$ & $(17.6)$ & - & $(15.5)$ & - & - & - & - \\
\hline 6-CDA & 1.403 & 1.382 & 1.401 & - & 1.811 & 1.848 & 120.2 & 121.1 & - & 101.3 \\
& $(303.9)$ & $(273.6)$ & $(66.5)$ & - & $(16.8)$ & $(12.5)$ & - & - & - & - \\
\hline 6-NCDA & 1.403 & 1.381 & 1.402 & - & 1.811 & 1.848 & 120.1 & 121.1 & - & 101.4 \\
& $(250.3)$ & $(270.6)$ & $(64.0)$ & - & $(16.5)$ & $(12.3)$ & - & - & - & - \\
\hline
\end{tabular}

Bull. Chem. Soc. Ethiop. 2016, 30(3) 
Table 3. Change in Gibbs free energy and total electronic energy for the chemical reactions considered, all calculated using B3LYP/6-311++G(2df,2p) and MP2/6-311++G(2df,2p).

\begin{tabular}{|c|c|c|c|c|c|c|c|}
\hline \multirow[b]{2}{*}{ Reaction } & \multirow[b]{2}{*}{ Channel } & \multirow[b]{2}{*}{ Reactants } & \multirow[b]{2}{*}{ Products } & \multicolumn{2}{|c|}{$\Delta G(\mathrm{~kJ} / \mathrm{mol})$} & \multicolumn{2}{|c|}{$\Delta E(\mathrm{~kJ} / \mathrm{mol})$} \\
\hline & & & & B3LYP & MP2 & B3LYP & MP2 \\
\hline 1 & 1 & $\mathrm{DA}+1 / 2 \mathrm{O}_{2}$ & $\mathrm{DAQ}+\mathrm{H}_{2} \mathrm{O}$ & -190.3 & -159.9 & -158.6 & -126.2 \\
\hline 2 & 2 & $\mathrm{DAQ}+1 / 2 \mathrm{O}_{2}$ & $\mathrm{DHI}+\mathrm{H}_{2} \mathrm{O}$ & -398.9 & -443.7 & -382.7 & -427.5 \\
\hline 3 & 1 and 2 & $\mathrm{DA}+1 / 2 \mathrm{O}_{2}$ & $\mathrm{LAC}+\mathrm{H}_{2} \mathrm{O}$ & -269.0 & -279.9 & -251.2 & -261.8 \\
\hline 4 & 1 and 2 & $\mathrm{DA}+\mathrm{O}_{2}$ & $\mathrm{AC}+2 \mathrm{H}_{2} \mathrm{O}$ & -537.6 & -501.1 & -486.1 & -450.2 \\
\hline 5 & 2 & $\mathrm{LAC}+1 / 2 \mathrm{O}_{2}$ & $+\mathrm{H}_{2} \mathrm{O}$ & -268.6 & -228.7 & -234.9 & -188.4 \\
\hline 6 & 2 & $\mathrm{DAQ}+1 / 2 \mathrm{O}_{2}$ & $\mathrm{AC}+\mathrm{H}_{2} \mathrm{O}$ & -347.3 & -343.7 & -327.5 & -323.9 \\
\hline 7 & 1 and 2 & $\mathrm{DA}+\mathrm{O}_{2}$ & $\mathrm{DHI}+2 \mathrm{H}_{2} \mathrm{O}$ & -589.2 & -592.9 & -541.3 & -553.8 \\
\hline 8 & 2 & $\mathrm{LAC}+1 / 2 \mathrm{O}_{2}$ & $\mathrm{DHI}+\mathrm{H}_{2} \mathrm{O}$ & -320.2 & -322.4 & -290.1 & -292.0 \\
\hline 9 & 1 and 3 & $\mathrm{DA}+$ cyst $+1 / 2 \mathrm{O}_{2}$ & $5-\mathrm{CDA}+\mathrm{H}_{2} \mathrm{O}$ & -230.0 & -212.1 & -261.7 & -255.7 \\
\hline 10 & 1 and 4 & $\mathrm{DA}+$ cyst $+1 / 2 \mathrm{O} 2$ & $6-\mathrm{CDA}+\mathrm{H}_{2} \mathrm{O}$ & -219.8 & -206.8 & -232.8 & -230.4 \\
\hline 11 & 1 and 3 & $\mathrm{DA}+$ ncyst $+1 / 2 \mathrm{O}_{2}$ & $5-\mathrm{NCDA}+\mathrm{H}_{2} \mathrm{O}$ & -232.9 & -213.9 & -259.2 & -256.9 \\
\hline 12 & 1 and 4 & $\mathrm{DA}+$ ncys $+1 / 2 \mathrm{O}_{2}$ & 6-NCDA $+\mathrm{H}_{2} \mathrm{O}$ & -218.8 & -207.6 & -238.3 & -233.5 \\
\hline
\end{tabular}

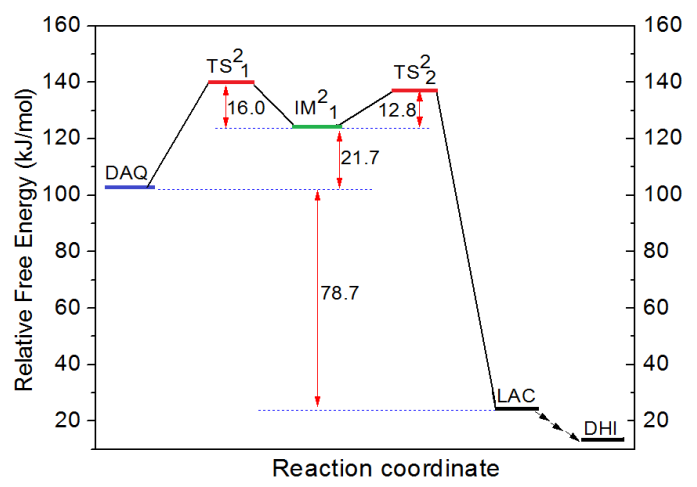

Figure 2. The free energy profiles (in $\mathrm{kJ} / \mathrm{mol}$ ) of reaction channel 2 calculated using B3LYP/6$311++\mathrm{G}(2 \mathrm{df}, 2 \mathrm{p})$. The superscripts represent the reaction channel and the subscripts represent the order of the transition state structures. IM stands for intermediate product and TS for transition state. For the purpose of clarity, only the major reactants and products are shown in the figure. For details of the reaction mechanisms used to calculate the change in Gibbs free energies refer to Scheme 2 and Table 3.

The scavengers

The possible scavengers used to study the diversion of melanin synthesis are cyst and ncyst. There are two protons which are susceptible to deprotonation in both molecules. Hence, this section of the paper presents the results from the calculations that were performed to identify the most stable and potential nucleophile generated either from cyst or ncyst. The PES scan for ncyst shows at least three conformers characterized by the highest stability. The first one forms a hydrogen bond with the carbonyl oxygen $(-\mathrm{O}-\mathrm{H}---\mathrm{O}=\mathrm{C}-$ and the second one points in the direction opposite to this bond. The conformer forming a hydrogen bond (1.679 $\AA$ ) with the carbonyl oxygen is found to be the most stable and dominant conformer on the potential energy surface, the latter being less stable by $5.2 \mathrm{~kJ} / \mathrm{mol}$ relative to the former. The same orientation was also obtained for the optimized structure of cyst.

The natural charges on sulfur and hydrogen atoms of the thiol group of cyst are -0.051 and +0.122 , respectively (see Table 1 ). On the other hand, the natural charges on oxygen and hydrogen atoms of the hydroxyl group of cyst listed in Table 1 are -0.703 and +0.480 , 
respectively. These charge differences indicate that there is stronger bond between oxygen and hydrogen of the hydroxyl group than that between sulfur and hydrogen atom of the thiol group. This makes the thiol hydrogen to be more susceptible to deprotonation. The same is also observed for ncyst. The second order perturbation theory analysis of the Fock matrix in NBO basis for the S-H and $\mathrm{O}-\mathrm{H}$ bonds of the thiol and hydroxyl groups, respectively, also provide supporting evidence for the formation of the stable thiolate nucleophile (see Table 1). Furthermore, the bond lengths of S-H and $\mathrm{O}-\mathrm{H}$ of cyst and their bond stabilization energies also favor the formation of the nucleophile from the thiolate group $(6.32 \mathrm{~kJ} / \mathrm{mol}$ and $44.6 \mathrm{~kJ} / \mathrm{mol}$, respectively, for S-H and $\mathrm{O}-\mathrm{H}$ bonds in cyst). The same trend has also been observed for ncyst. Therefore, in agreement with the experimental results, [53] the thiol group is deprotonated to give the thiolate ion, which then acts as a potential nucleophile for the reactions studied in the Reaction channels 3 and 4 section. This high reactivity of the thiol group of cysteine is also one of the reasons for its use in numerous biological activities.

Reaction channels 3 and 4

In section Reaction channels 1 and 2, we concluded that in order to divert the synthetic pathway of melanin, we need to add the scavengers before the start of the internal cyclization reaction of DAQ. In the Scavengers section, we showed that the thiolate anion is a more potent nucleophile than the hydroxyl anion both generated from the two scavengers, cyst and ncyst. In this section of the paper, we present the reaction mechanism and the possible products generated from DAQ and the scavengers with an attempt to divert the melanin synthetic pathway. As discussed in section Reaction channels 1 and 2, C5 of DAQ has a negative natural charge that is smaller than $\mathrm{C} 6$ which results in $\mathrm{C} 5$ being a dominant electrophile leading to the formation of 5-CDA or 5NCDA, respectively, from cyst and ncyst. Based on this, the Michael addition reactions of DAQ with cyst for the formation of 5-CDA and 6-CDA are shown in Scheme 3, reaction channels 3 and 4 , respectively. The nucleophile generated from cyst attacks DAQ at either C5 or C6 positions to form 5-CDA or 6-CDA, respectively, in channel 3 and channel 4 (see Scheme 3). Similarly, the products from the nucleophile generated from ncyst are 5-NCDA and 6-NCDA.

From the thermodynamic energies listed in Table 3, it is shown that the formation of 5-CDA from the reaction of cyst and DA (reaction 9 in Table 3 ) is accompanied by higher change in Gibbs free energy $(\Delta G=-230.0 \mathrm{~kJ} / \mathrm{mol}$ and $\Delta E=-261.7 \mathrm{~kJ} / \mathrm{mol}$ using B3LYP), and it is the major product in reaction channel 3 (see Table 3 and Scheme 3). On the other hand, the formation of 6-CDA (reaction 10 of Table 3 ) is relatively less favored with a $\Delta G$ value of -219.8 $\mathrm{kJ} / \mathrm{mol}$ compared to 5-CDA, i.e. reaction channel 3 is energetically favored over reaction channel 4. The formation of 5-NCDA from the reaction of ncyst and DA (reaction 11 of Table 3 ) is accompanied by a change in Gibbs free energy of $-232.9 \mathrm{~kJ} / \mathrm{mol}$, which is comparable to that of 5-CDA. This indicates that both cyst and ncyst are potential scavengers to divert the melanin synthetic pathway.

The natural charges from the NBO analysis listed in Table 1 show that the charges of $\mathrm{C} 5$ and $\mathrm{S}$ of 5-CDA are -0.231 and +0.238 , respectively. The charges on $\mathrm{C6}$ and $\mathrm{S}$ of 6-CDA respectively are -0.208 and +0.208 . This shows the presence of a slightly weaker C6-S bond of 6-CDA than C5-S of 5-CDA, which further indicates that cyst forms a stronger bond to C5 than C6. Once 5-CDA or 6-CDA is formed in the reactions, there could also be a possibility for internal cyclization reactions. But as can be seen from the natural charges listed in Table 1, the immediate neighboring carbon atom, $\mathrm{C} 2$, to the ethyl-amino group of all the adducts has negative natural charge which means that $\mathrm{C} 2$ is protected from the nucleophilic attack by the nitrogen atom of the amino group. Therefore, once these products are formed, internal cyclization is less favored. 


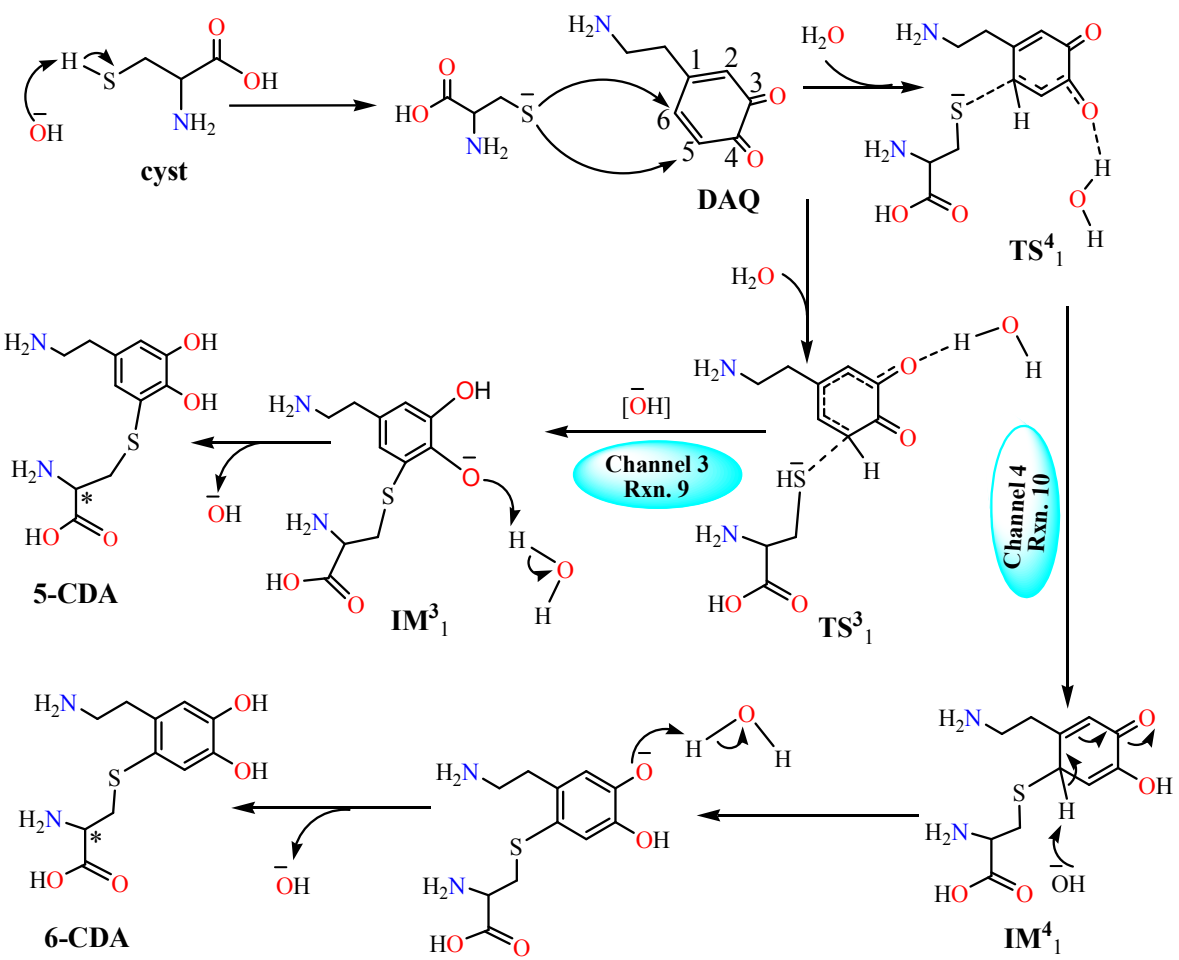

Scheme 3. The possible reaction pathways for the reaction of dopaminoquinone in the presence of L-cysteine, for the purpose of clarity some of the reaction processes are omitted. Refer to Table 3 for the reaction numbers.

The optimized structural parameters listed in Table 2 show that the C1-C6 and C4-C5 bond lengths of all the products are shorter compared to DAQ. This shortening of the bonds is due to the fact that the C1-C6 and C4-C5 bonds in the products have adopted partial double bond character during the nucleophilic attack. The large charge differences between $\mathrm{C} 5$ and $\mathrm{S}$ than $\mathrm{C} 6$ and $\mathrm{S}$ indicate that the $\mathrm{C} 5-\mathrm{S}$ bond length in 5-CDA with a stabilization energy of $E(2)=19.2$ $\mathrm{kJ} / \mathrm{mol}$ is slightly shorter than C6-S with a stabilization energy of $E(2)=16.8 \mathrm{~kJ} / \mathrm{mol}$ in 6-CDA (see Table 2). The bond stabilization energy differences also indicate that the $\mathrm{C} 5-\mathrm{S}$ bond of 5CDA is slightly stronger than that of 6-CDA and 6-NCDA. The overall analysis of the stabilization energies listed in Table 2 indicates that the new $\mathrm{C} 5-\mathrm{S}$ bond formed from the nucleophilic attack at $\mathrm{C} 5$ position is more stable in both 5-CDA and 5-NCDA than the C6-S bond of 6-CDA and 6-NCDA.

The bond length of $\mathrm{C} 2$ '-S of 5-CDA is shorter than that of 6-CDA, see Table 2. Despite the negative natural charge on $\mathrm{C} 5$ and positive natural charge on $\mathrm{S}$ of 5-NCDA, the bond length of $\mathrm{C} 2^{\prime}-\mathrm{S}$ is similar to that of 5-CDA, but slightly shorter than the $\mathrm{C} 2^{\prime}-\mathrm{S}$ bond of 6-CDA. It is also observed that the bond stabilization energy of C2'-S of 5-CDA is $E(2)=16.5 \mathrm{~kJ} / \mathrm{mol}$ which is greater than that of 5-NCDA with $E(2)=15.5 \mathrm{~kJ} / \mathrm{mol}$ and $6-\mathrm{CDA}$ with a bond stabilization energy of $E(2)=12.5 \mathrm{~kJ} / \mathrm{mol}$ (see Table 2). This also indicates that the bond stabilization energy favors the formation of a bond by the scavengers at the C5 position of DAQ. Noteworthy is also that the $\mathrm{C} 2$ '-S bond in the products is stabilized compared to that of the nucleophiles. For 
instance, $E(2)$ of $\mathrm{C}^{\prime}-\mathrm{S}$ of ncyst is $11.5 \mathrm{~kJ} / \mathrm{mol}$ and that of $5-\mathrm{CDA}$ and $5-\mathrm{NCDA}$ is $16.5 \mathrm{~kJ} / \mathrm{mol}$ and $15.5 \mathrm{~kJ} / \mathrm{mol}$, respectively (see Table 2 ).

In addition to the analysis of the thermodynamic energies of the reactions, we also studied the kinetics of the transformation of the reactants to products considered in this section. The energy profile for the formation of 5-CDA and 6-CDA is presented in Figure 3. There are two transition states for both reaction channels 3 and 4 (see Scheme 3 for the reaction channels). The barrier for the first transition state of reaction channel $3\left(\mathrm{TS}_{1}^{3}\right)$ is $21 \mathrm{~kJ} / \mathrm{mol}$, whereas that of reaction channel $4\left(\mathrm{TS}_{1}^{4}\right)$ is $26.3 \mathrm{~kJ} / \mathrm{mol}$ (see Figure 3 ). Once DAQ is scavenged by either cyst or ncyst and reached to the first transition state, the formation of 5-CDA in reaction channel 3 is energetically favored by $5.3 \mathrm{~kJ} / \mathrm{mol}$ over the formation of 6-CDA in reaction channel 4 . The second transition state of channel $3\left(\mathrm{TS}^{3}{ }_{2}\right)$ is also favored by $8.5 \mathrm{~kJ} / \mathrm{mol}$ than $\mathrm{TS}_{2}^{4}$ of channel 4 , showing that the formation of 5-CDA is supported also by the kinetic parameters presented in Figure 3.

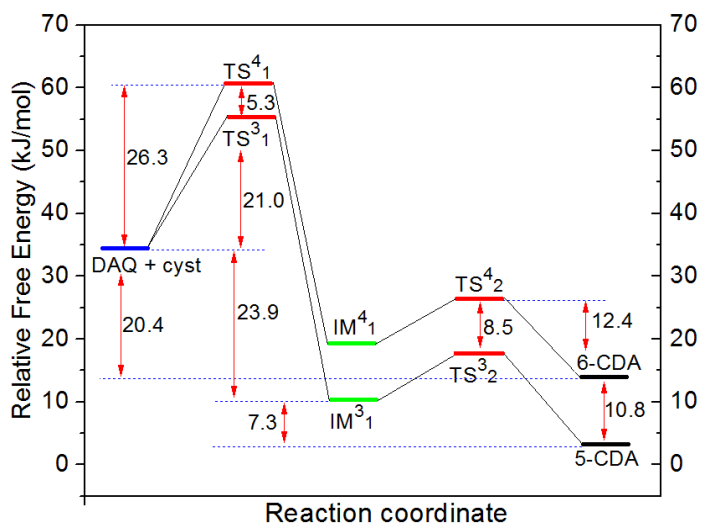

Figure 3. The free energy profiles (in $\mathrm{kJ} / \mathrm{mol}$ ) of reaction channels 3 and 4 calculated using B3LYP/6-311++G(2df,2p). The superscripts represent the reaction channels and the subscripts represent the transition state structures. IM stands for intermediate products and TS for transition state structures. For the purpose of clarity only the major reactants and products are shown in the figure. For details of the reaction mechanisms used to calculate the change in Gibbs free energies (in $\mathrm{kJ} / \mathrm{mol}$ ) refer to Table 3 and Scheme 3.

\section{CONCLUSION}

In this study, the reaction mechanisms for the synthesis as well as possible reaction pathways for the diversion of melanin synthesis were investigated using B3LYP functional and 6$311++\mathrm{G}(2 \mathrm{df}, 2 \mathrm{p})$ basis set. In the absence of the reductants, like cyst and ncyst, dopaminoquinone undergoes cyclization reactions leading to the formation of melanin. In the presence of cyst, dopaminoquinone is scavenged and the melanin synthetic pathway is diverted by forming 5-CDA and 6-CDA from cyst, whereas 5-NCDA and 6-NCDA from ncyst. Our results show that under standard conditions cyst seems to be competitive with the internal cyclization process of dopaminoquinone. Moreover, the results indicate that carefully chosen nucleophiles like cyst in an appropriate dose can successfully divert the melanin synthetic pathway. Our theoretical results are in agreement with the experimental findings about melanin pigmentation of yellow and black gerbils and other mammals in which the velocity and specificity of the reaction pathways are regulated by the melanogenesis related enzymes, of which the most important is tyrosinase [54-56]. In the Introduction section, we have discussed the significance of the diversion of the melanin synthetic pathway in biological systems [57]. For instance, neuromelanin released by the dying neurons can contribute to the activation of 
neuroglia that triggers neuroinflammation which characterizes Parkinson's disease [58]. Under this aspect, we believe that our present work is important for the understanding of the favored reaction pathways leading to the diversion of the melanin synthetic pathway on the molecular level.

\section{ACKNOWLEDGMENTS}

The Chemistry Departments of Hawassa and Haramaya Universities are greatly acknowledged for computational facilities. TBD also acknowledges the Research Council of Norway through a Centre of Excellence Grant (Grant No. 179568). The Norwegian Supercomputing Program (NOTUR) through a grant of computer time (nn4654k) is also gratefully acknowledged for additional calculations.

\section{REFERENCES}

1. Clark, W.H., Jr.; Hibbs, R.G. J. Biophys. Biochem. Cytol. 1958, 4, 679.

2. Deibel, R.M.B.; Chedekel, M.R. J. Am. Chem. Soc. 1984, 106, 5884.

3. Qiu, L.; Zhang, M.; Sturm, R.A.; Gardiner, B.; Tonks, I.; Kay, G.; Parsons, P.G. J. Investig. Dermatol. 2000, 114, 21.

4. Hopkins, T.; Kramer, K.J. Annu. Rev. Entomol. 1992, 37, 273.

5. Kastner, A.; Hirsch, E.C.; Lejeune, O.; Javoy-Agid, F.; Rascol, O.; Agid, Y. J. Neurochem. 1992, 59, 1080.

6. Zhang, F.; Dryhurst, G. Bioorg. Chem. 1993, 21, 392.

7. Heacock, R.A. Chem. Rev. 1959, 59, 181

8. Mundy, N.I. PLoS Biol. 2007, 5, e250.

9. Paine, C.; Sharlow, E.; Liebel, F.; Eisinger, M.; Shapino, S.; Seiberg, M. J. Invest. Dermatol. 2001, 116, 587.

10. Roh, J.S.; Han, J.Y.; Kin, J.H.; Hwang, J.K. Biol. Pharm. Bull. 2004, 27, 1976.

11. Mori-Hongo, M.; Yamaguchi, H.; Warashina, T.; Miyase, T. J. Nat. Prod. 2008, 72, 63.

12. Ogi, T.; Higa, M.; Maruyama, S. J. Agric. Food. Chem. 2011, 59, 1109.

13. Zoccarato, F.; Toscano, P.; Alexandre, A. J. Biol. Chem. 2005, 280, 15587.

14. Benedetto, J.P.; Ortonne, J.P.; Voulot, C.; Khatchadourian, C.; Prota, G.T., J. J. Invest. Dermatol. 1982, 79, 422.

15. Fengju, B.; Serrine, S.L.; Terrence, J.M. Chem. Res. Toxicol. 1999, 12, 1150.

16. Robertson, N.W.; Blecher, S.R. Biochem. Cell. Biol. 1987, 65, 658.

17. Butler, J.D.; Zatz, M. J. Clin. Invest. 1984, 74, 411.

18. Issels, R.D.; Nagele, A.; Eckert, K.G.; Wilmanns, W. Biochem. Pharmacol. 1988 37, 881.

19. Bergamini, A.; Capozzi, M.; Ghibelli, L. J. Clin. Invest. 1994 93, 2251.

20. Carstam, R.; Brinck, C. Biochem. Biophys. Acta 1991, 152, 1097.

21. Xu, R.; Huang, X.; Kramer, K.J.; Hawley, M.D. Bioorg. Chem. 1996, 24, 110.

22. Rosengren, E.; Eva Linder-Eliasson, I.; Carlsson, A. J. Neural Transm. 1985, 63, 247.

23. Irmgard, P.; Sergio, C.; Jorge, L.; Carolina, P.; Rebecca, G.; Alejandra, R.; Pablo, C.; Juan, S. Neurotox. Res. 2007, 12, 125.

24. Hastings, T.G.; Lewis, D.A.; Zigmond, M.J. Proc. Natl. Acad. Sci. USA 1996, 93, 1956.

25. Matthew, J.P.; Venkataraman, A.G.G.; Thomas, J.M. Free Radic. Biol. Med. 1999, 27, 271.

26. Nishihira, J.; Tachikawa, H. J. Theor. Biol. 1997, 185, 157.

27. Aliste, M.P. J. Mol. Struct: THEOCHEM 2000, 507, 1.

28. Mohammad-Shiri, H.; Ghaemi, M.; Riahi, S.; Akbari-Sehat, A. Int. J. Electrochem. Sci. 2011, 6, 317.

29. Zheng, J.; Zhao, Y.; G. Truhlar, D. J. Chem. Theory Comput. 2007, 3, 569.

30. Zhao, Y.; Gonzalez-Garcia, N.; G. Truhlar, D. J. Phys. Chem. A 2005, 109, 2012.

31. Guner, V.; Khuong, K.S.; Leach, A.G.; Lee, P.S.; Bartberger, M.D.; Houk, K.N. J. Phys. Chem. A 2003, 107, 11445.

32. Curtiss, L.A.; Raghavachari, K.; Redfern, P.C.; Pople, J.A. J. Chem. Phys. 1997, 106, 1063. 
33. Vosko, S.H.; Wilk, L.; Nusair, M. Can. J. Phys. 1980, 58, 1200.

34. Stephens, P.J.; Devlin, F.J.; Chabalowski, C.F.; Frisch, M.J. J. Phys. Chem. 1994, 98, 11623.

35. Becke, A.D. J. Chem. Phys. 1993, 98, 5648.

36. Lee, C.; Yang, W.; Parr, R.G. Phys. Rev. B. 1988, 37, 785.

37. Krishnan, R.; Binkley, J.S.; Seeger, R.; Pople, J.A. J. Chem. Phys. 1980, 72, 650.

38. Møller, C.; Plesset, M.S. Phys. Rev. A 1934, 46, 0618.

39. Head-Gordon, M.; Pople, J.A.; Frisch, M.J. Chem. Phys. Lett. 1988, 153, 503.

40. Frisch, M.J.; Trucks, G.W.; Schlegel, H.B.; Scuseria, G.E.; Robb, M.A.; Cheeseman, J.R.; Scalmani, G.; Barone, V.; Mennucci, B.; Petersson, G.A.; Nakatsuji, H.; Caricato, M.; Li, X.; Hratchian, H.P.; Izmaylov, A.F.; Bloino, J.; Zheng, G.; Sonnenberg, J.L.; Hada, M.; Ehara, M.; Toyota, K.; Fukuda, R.; Hasegawa, J.; Ishida, M.; Nakajima, T.; Honda, Y.; Kitao, O.; Nakai, H.; Vreven, T.; Montgomery, Jr., J.A.; Peralta, J.E.; Ogliaro, F.; Bearpark, M.; Heyd, J.J.; Brothers, E.; Kudin, K.N.; Staroverov, V.N.; Keith, T.; Kobayashi, R.; Normand, J.; Raghavachari, K.; Rendell, A.; Burant, J.C.; Iyengar, S.S.; Tomasi, J.; Cossi, M.; Rega, N.; Millam, J.M.; Klene, M.; Knox, J.E.; Cross, J.B.; Bakken, V.; Adamo, C.; Jaramillo, J.; Gomperts, R.; Stratmann, R.E.; Yazyev, O.; Austin, A.J.; Cammi, R.; Pomelli, C.; Ochterski, J.W.; Martin, R.L.; Morokuma, K.; Zakrzewski, V.G.; Voth, G.A.; Salvador, P.; Dannenberg, J.J.; Dapprich, S.; Daniels, A.D.; Farkas, O.; Foresman, J.B.; Ortiz, J.V.; Cioslowski, J.; Fox, D.J. Gaussian 09, Revision A.02, Gaussian, Inc.: Wallingford CT; 2009. 41. Tomasi, J.; Mennucci, B.; Cammi, R. Chem. Rev. 2005, 105, 2999.

42. Weinhold, F.; Landis, C.R. Discovering Chemistry with Natural Bond Orbitals, John Wiley and Sons: New Jersey; 2012.

43. Weinhold, F.; Landis, C.R. Chem. Educ. Res. Pract. Eur. 2001, $2,91$.

44. Reed, A.E.; Weinstock, R.B.; Weinhold, F. J. Chem. Phys. 1985, 83735.

45. Foster, J.P.; Weinhold, F. J. Am. Chem. Soc. 1980, 102, 7211.

46. Demissie, T.B.; Admassie, S.; Mohammed, A.M.; Mammo, W. Bull. Chem. Soc. Ethiop. 2010, 24, 93.

47. Graumann, R.; Paris, I.; Martinez-Alvarado, P.; Rumanque, P.; Perez-Pastene, C.; Cardenas, S.; Marin, P.; Diaz-Grez, F.; Caviedes, R.; Caviedes, P.; Segura-Aguilar, J. Pol. J. Pharmacol. 2002, 54, 573.

48. Van Scott, E.J.; Rothman, S.; Greene, C.R. J. Invest. Dermat. 1953, $20,111$.

49. Jimenez, M.; Garcia-Carmona, F.; Garcia-Canovas, F.; Iborra, J.L.; Lozano, J.A.; Martinez, F. Arch. Biochem. Biophys. 1984, 235, 438.

50. Arriagada, C.; Paris, I.; Sanchez de las Matas, M.J.; Martinez-Alvarado, P.; Cardenas, S.; Castañeda, P.; Graumann, R.; Perez-Pastene, C.; Olea-Azar, C.; Couve, E.; Herrero, M.T.; Caviedes, P.; Segura-Aguilar, J. Neurobiol. Disease 2004, 16, 468.

51. Patricia, M.; Huenchuguala, S.; Paris, I.; Segura-Aguilar, J. Parkinson's Disease 2012, 2012, 13.

52. Paris, I.; Muñoz, P.; Huenchuguala, S.; Couve, E.; Sanders, L.H.; Greenamyre, J.T.; Caviedes, P.; Segura-Aguilar, J. Toxicol. Sci. 2011, 121, 376.

53. Bulaj, G.; Kortemme, T.; Goldenberg, D.P. Biochem. 1998, 37, 8965.

54. Slominski, A.; Tobin, D.J.; Shibahara, S.; Wortsman, J. Physiol. Rev. 2004, 84, 1155.

55. Pawelek, J.; Körner, A. Am. Sci. 1982, 70, 136.

56. Hearing, V.J.; Tsukamoto, K. FASEB J. 1991, 5, 2902.

57. Ling Qiu, M.Z.; Sturm, R.A.; Gardiner, B.; Tonks, I.; Kay, G.; Parsons, P.G. J. Invest. Dermatol. 2000, 114, 21.

58. Zucca, F.; Basso, E.; Cupaioli, F.; Ferrari, E.; Sulzer, D.; Casella, L.; Zecca, L. Neurotox. Res. 2014, 25, 13. 